\title{
An overview of resource utilization of steel slag as absorbent material for waste water treatment
}

\author{
Chan $\mathrm{Yu}^{1,2}$, Wei Zhang ${ }^{1,2}$, Fei Gao ${ }^{1,2}$, Huawei Huang ${ }^{1,2}$ and Liangyuan Zhao ${ }^{1,2, *}$ \\ ${ }^{1}$ Basin Water Environmental Research Department, Changjiang River Scientific Research Institute, Wuhan, Hubei, 430010, China \\ ${ }^{2}$ Key Lab of Basin Water Resource and Eco-Environmental Science in Hubei Province, Wuhan 430010, China
}

\begin{abstract}
With the rapid development of the steel industry, the accumulation of steel slag increases year by year, occupying a large amount of farm land and leading the problem of environmental pollution and safety hazards. The current comprehensive utilization rate of steel slag is still very low in China, far behind the developed countries. The low comprehensive utilization rate of steel slag is a stumbling block to the green and sustainable development of the Yangtze River Economic Belt. Improving the comprehensive utilization rate of steel slag is an imperative way to resolve these problems and to realize sustainable development for the steel enterprise. Steel slag presents porous structure and large surface area; in addition, it is easy to separate from water due to its high density. Therefore, the application of steel slag in industrial waste water treatment has received intensive attention in recent years. This paper systematically introduced the research progress of steel slag resource utilization as absorbent materials for waste water and proposed the important improved method and critical problems for steel slag as absorbent materials.
\end{abstract}

\section{Introduction}

Reducing, reusing and recycling are the main methods to deal with solid waste. Steel slag is a kind of solid waste produced in the process of steel production. For every 1 ton of steel produced, $125-140 \mathrm{~kg}$ steel slag will be produced. From the early 1990s to the end of 2018, the amount of steel slag deposited in storage yard exceeded 1.8 billion tons. Landfill is the most commonly used method to dispose of steel slag, but this method occupies a large amount of agricultural land. In addition, unplanned and unreasonable landfill methods also bring great safety risks to the environment. Now, the utilization rate of steel slag in China is only about 30\% at present. Therefore, further expanding the application range of steel slag and improving the utilization rate of steel slag are the main means to solve this problem.

At present, the resource utilization of steel slag is mainly used as materials for metallurgical furnace, admixture and aggregate of concrete, paving and construction materials, materials for waste water treatment, and fertilizer in agriculture etc. Steel slag has high mechanical strength, strong acid resistance, strong alkali resistance, good thermal stability and its unique chemical composition and properties, which are suitable for treatment of waste water. In addition, the application of steel slag in waste water is economical and effective because of its low price and large dosage, and it is also an important way to recycle steel slag. In this paper, the application of steel slag as adsorbent material for waste water treatment is introduced.

\section{Physical and chemical characteristics of steel slag}

Steel slag is a kind of solid waste produced in steelmaking process, which accounts for $12 \%-15 \%$ of crude steel output. The steel slag mainly consists of $\mathrm{CaO}$, $\mathrm{SiO}_{2}, \mathrm{P}_{2} \mathrm{O}_{5}, \mathrm{FeO}, \mathrm{Fe}_{2} \mathrm{O}_{3}, \mathrm{MgO}, \mathrm{MnO}$ and $\mathrm{Al}_{2} \mathrm{O}_{3}$ [1]. The chemical component of steel slag varies with the furnace type, steel grades and pretreatment method. And the harmless pretreatment technology of steel slag mainly include hot spilled method, BSSF method, water quenching method, hot closed pot method, cold abandon method and so on [2]. The main purpose of these methods is to pelletize hot steel slag so that the slag and iron can be separated effectively and the steel slag tailings with stable performance can be used comprehensively in the later stage [3].

Through toxicity characteristic leaching procedure test conducted in the USA, steel slag should not be considered a hazardous waste and could be used for different purposes. In this experiment, the trace element including nickel, chromium, lead, zinc, titanium, and vanadium were observed, but there is no metals in the leachates exceed the TCLP criterion concentrations. Moreover, organic chemicals do not exist in the slag [4]. Therefore, the environmental issues can be ignored when expanding the application of steel slag. 


\section{Utilization of absorbent materials for waste water treatment}

In recent years, more and more researchers pay attention to the application of steel slag in waste water treatment. Steel slag is a promising adsorption material. However, the adsorption efficiency of steel slag is affected by many factors, such as lattice aperture size, channel dredging, cation position and ratio of $\mathrm{Si}$ and $\mathrm{Al}$, etc., the adsorption efficiency is still low, so it needs to be modified. Now, the main modification methods of steel slag are inorganic modification, high temperature activation modification and composite modification. There are three types of inorganic modification: acid modification, alkali modification and salt modification. High temperature activation modification is a method of heat treatment of steel slag under high temperature conditions. The modification temperature of steel slag is generally in the range of $400-1100{ }^{\circ} \mathrm{C}$. Composite modification refers to one or more materials mixed with steel slag and then through inorganic modification or high temperature modification method. At present, modified steel slag is mainly used to adsorb heavy metal ions and organic pollutants in waste water.

\subsection{Removal of heavy metal ions}

Steel slag has a porous structure as well as a large specific surface area, in addition, it is easily hydrolyzed and ionized $\mathrm{Ca}^{2+}, \mathrm{Fe}^{2+}, \mathrm{OH}-$ and hydroxyl groups $\mathrm{SOH}$ in aqueous solution, which make steel slag a good adsorbent for heavy metal ions. And many reported studies have shown that steel slag have a high removal rate for metal ions in waste water. The removal mechanism of steel slag for heavy metal ions includes physical adsorption and chemical adsorption. The physical adsorption of steel slag mainly depends on the van der Waals force between steel slag and pollutants. The physical adsorption of steel slag is determined by its specific surface area and porous nature. The larger the specific surface area and the more the pores, the stronger the physical adsorption capacity is. When there is electron transfer, chemical bond formation and fracture between adsorbent and adsorbent, it becomes chemical adsorption, which mainly includes chemical precipitation, reduction, cation exchange, surface coordination etc. The removal efficiency of heavy metal ions is mainly affected by $\mathrm{pH}$ value of the solution, initial concentration of heavy metal ions, composition of steel slag and the particle sizes of steel slag etc.

In the process of waste water discharge, heavy metal ions with considerable degree are deposited in natural water bodies. Among these heavy metal ions, $\mathrm{Pb}^{2+} 、 \mathrm{Cr}^{3+}\left(\mathrm{Cr}^{6+}\right) 、 \mathrm{Hg}^{2+}$ and $\mathrm{Cd}^{2+}$ are especially toxic. The research progress of steel slag as adsorbent for adsorbing $\mathrm{Pb}^{2+} 、 \mathrm{Cr}^{3+}\left(\mathrm{Cr}^{6+}\right) 、 \mathrm{Hg}^{2+}$ and $\mathrm{Cd}^{2+}$ are described in detail below.

\subsubsection{Pb ions removal}

$\mathrm{Pb}$-containing waste water mainly comes from electroplating, machinery and chemical industries. As a highly toxic metal, $\mathrm{Pb}$ is not readily excrete and can cause serious harm to human health. There are strict discharge standards for $\mathrm{Pb}$-containing waste water in national standards.

The adsorption effect of steel slag with different pretreatment and modification methods on $\mathrm{Pb}^{2+}$ is different. CurkovicL et al. found that electroslag had a better ability to remove $\mathrm{Pb}^{2+}$, and its adsorption capacity was higher than $20 \mathrm{mg} / \mathrm{g}$ [5]. Shen et al. used steel slag modified by $\mathrm{H}_{2} \mathrm{SO}_{4}$ to adsorb $\mathrm{Pb}^{2+}$ in waste water, and the removal rate was increased from $60 \%$ of the original steel slag to $96.94 \%$. It was speculated that the adsorption mechanism of modified steel slag on lead was mainly based on chemical precipitation and ion exchange (see Fig. 1) [6]. In addition, Xiao et al. compared the removal effect of acid and alkali modification methods on $\mathrm{Pb}^{2+}$, and the results showed that both methods improved the adsorption effect of steel slag. And under the optimal conditions, the removal rates of $\mathrm{Pb}^{2+}$ from acid and alkali modified steel slag were $98.3 \%$ and $97.3 \%$, respectively, with no significant difference [7].

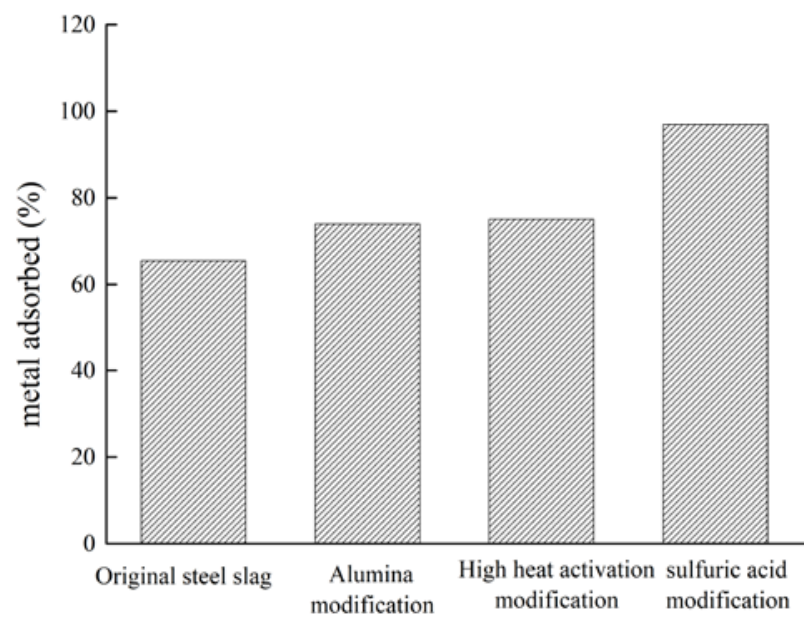

Fig. 1. Comparison of removal effects of steel slag with different modification methods on $\mathrm{Pb}$-containing waste water.

\subsubsection{Cr ions removal}

Cr-containing waste water mainly comes from mineral processing, metal smelting and dye industries. $\mathrm{Cr}$ element mainly exists in the form of $\mathrm{Cr}^{3+}$ and $\mathrm{Cr}^{6+}$, and $\mathrm{Cr}^{6+}$ is more toxic than $\mathrm{Cr}^{3+}$. $\mathrm{Cr}^{6+}$ is a common carcinogen and there are strict discharge standards for $\mathrm{Cr}^{6+}$ and total chromium in national standards.

Ma Yan et al. found that the removal rate of $\mathrm{Cr}^{6+}$ adsorbed by steel slag was as high as $99.9 \%$. With the decrease of slag particle size, the increase of the reaction time and slag dosage, the removal rate of $\mathrm{Cr}^{6+}$ of steel slag increased significantly. The removal of $\mathrm{Cr}^{6+}$ by steel slag mainly depends on the reduction of steel slag (see Fig. 2) [8].Jiang et al. treated $\mathrm{Cr}^{6+}$ in leachate with high 
temperature modified steel slag and found that the modified steel slag adsorbed well only under acidic conditions [9]. In addition, ma et al. 's study on the removal of $\mathrm{Cr}^{3+}$ in sewage showed that the adsorption and removal rate of $\mathrm{Cr}^{3+}$ by steel slag could reach more than $99 \%$, and the $\mathrm{pH}$ value and initial concentration of the solution had little influence on the adsorption effect of $\mathrm{Cr}^{3+}$ by steel slag, which was stable at more than $99 \%$ [10].

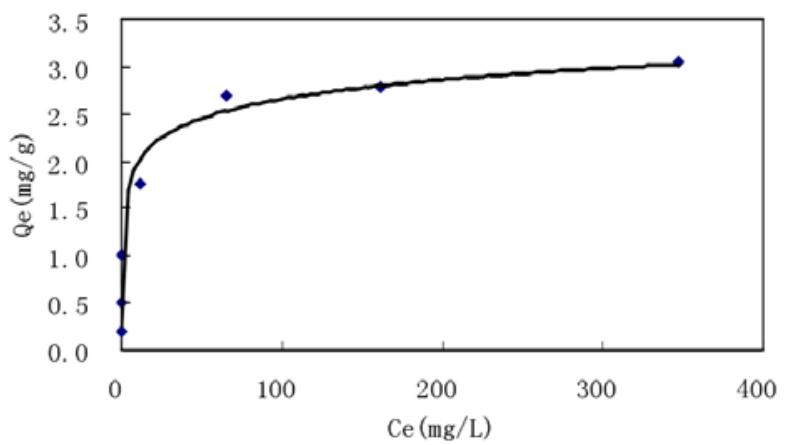

Fig. 2. The relationship between equilibrium adsorption and equilibrium concentration.

\subsubsection{Hg ions removal}

Hg-containing waste water mainly comes from plastics, chemical industry and electronics industry. It is is the most toxic element in heavy metal pollution.

Xia et al. modified steel slag with $15 \%$ sulfuric acid to adsorb $\mathrm{Hg}^{2+}$ in seawater. The results showed that the $\mathrm{Hg}^{2+}$ removal efficiency of modified steel slag is $95.9 \%$ under the optimal condition in room temperature, which is $25.9 \%$ higher than that of unmodified steel slag. The adsorption property of the modified steel slag is similar to that of the common adsorbent activated carbon, but compared with the activated carbon, the steel slag is more widely available and has a broad application prospect [11].

\subsubsection{Cd ions removal}

Cd-containing waste water mainly comes from pigment, electroplating and other industries. Cd element can not only cause water pollution, but also accumulate in human body through food chain and harm human health.

Zhang et al. activated modified steel slag at high temperature for adsorption of $\mathrm{Cd}$. Under the optimal conditions, the removal rate of $\mathrm{Cd}$ from modified steel slag reached 94\%. The analytical regeneration experiment results of steel slag after adsorption showed that $\mathrm{NaOH}$ and high temperature could desorption and regeneration of saturated steel slag and regain the ability of $\mathrm{Cd}^{2+}$ adsorption [12].

Lai et al. adsorbed $\mathrm{Cd}^{2+}$ in waste water with montmontillonite composite modified steel slag, and then investigated the influence of $\mathrm{Cu}^{2+}$ and $\mathrm{Pb}^{2+}$ on $\mathrm{Cd}^{2+}$ competitive adsorption. The experimental results showed that the composite modified steel slag had the best adsorption effect on $\mathrm{Cd}$, with the removal rate reaching over 97\%. The adsorption effect of $\mathrm{Pb}^{2+}$ on $\mathrm{Cd}^{2+}$ is larger than $\mathrm{Cu}^{2+}[13]$.

DUAN J et al mixed steel slag with $\mathrm{Al}(\mathrm{OH})_{3}$ with a ratio of $4: 3$, then heated for $2 \mathrm{~h}$ at $700{ }^{\circ} \mathrm{C}$ to adsorb $\mathrm{Cd}^{2+}$ in the waste water. Results showed the saturated adsorption capacity of steel slag after composite modification increased from 5.917 to $12.52 \mathrm{mg} / \mathrm{g}$, which was 2.2 times that of unmodified steel slag (see Fig. 3) [14].

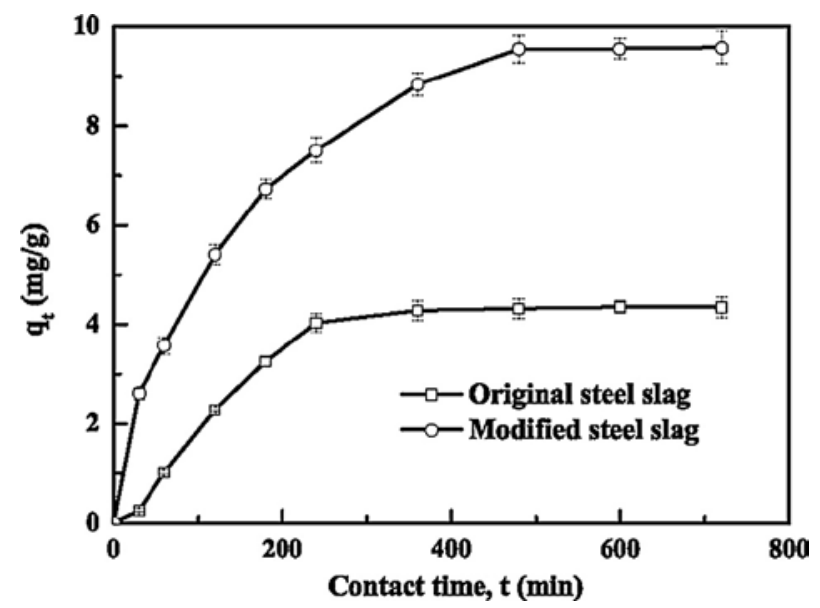

Fig. 3. Adsorption isotherms of Cd(II) onto modified steel-making slag.

\subsection{Removal of organic pollutants}

In addition to the good removal efficiency in the adsorption of heavy metal ions, steel slag as a separated adsorbent can also be used to remove aqueous phosphorous and ammonium nitrogen. The research progress of steel slag as adsorbent for adsorbing phosphorous and ammonium nitrogen are described in detail below.

\subsubsection{Phosphorus removal}

Unlike carbon and nitrogen, phosphorus is not renewable in the natural cycle, and phosphorus is the main limiting factor of water eutrophication. Therefore, how to remove and recover phosphorus from waste water is an important aspect of current research. Developing the application of steel slag in waste water is an economical and effective method, which is of great significance for phosphorus removal from waste water. The use of steel slag as phosphorus removal adsorbent can be used as either the strengthening treatment after biological phosphorus removal or as a separate phosphorus removal method.

Zheng et al. prepared a modified steel by alkali modification and high temperature activation modification and studied its phosphorus removal effect on the effluent after biological treatment. Under optimal conditions, the removal rate reached 93\% after adsorption by modified steel slag. And the theoretical saturated capacity was $1.98 \mathrm{mg} / \mathrm{g}$ [15]. Duan et al. prepared modified steel slag by mixing steel slag with $\mathrm{Al}(\mathrm{OH})_{3}$ and calcination at high temperature by the 
method of composite modification.Under the optimal conditions, the maximum adsorption capacity of phosphorus was $1.37 \mathrm{mg} / \mathrm{g}$, and chemical adsorption was the main adsorption process [16]. Wang et al. prepared a kind of non-sintering composite steel slag filter by compound modification. There was no need of high temperature sintering during the preparation process of the non-sintering composite steel slag filter, and the process had the characteristics of low preparation cost and little pollution to environment. The prepared filter was easier to be applied in practical engineering. Moreover, the composite filter performed high efficiency of phosphorus removal, and the removal rate of phosphorus was always above $80 \%$. The maximum adsorption capacity of phosphorus was $3.21 \mathrm{mg} / \mathrm{g}$, and the phosphorus removal was dominated by chemical adsorption [17].

\subsubsection{Ammonium nitrogen removal}

Duan et al. prepared modified steel slag by mixing steel slag with $\mathrm{Al}(\mathrm{OH})_{3}$ and calcination at high temperature by the method of composite modification. Under the optimal conditions, the maximum adsorption capacity of phosphorus was $3.24 \mathrm{mg} / \mathrm{g}$, and ion exchange and physical adsorption were the main adsorption process [16].

Cheng et al. designed 5 factors 4 levels orthogonal experiment with ammonia nitrogen removal efficiency as experimenal index. The results indicated that ammonia nitrogen initial quality concentration has the greatest effect and the adsorption time has least effect on ammonia nitrogen adsorption by modified steel. Besides the research results showed that the mechanism is surface layer adsorption and the theory quantity of adsorption is $2.85 \mathrm{mg} / \mathrm{g}$ (see Fig. 4) [18].

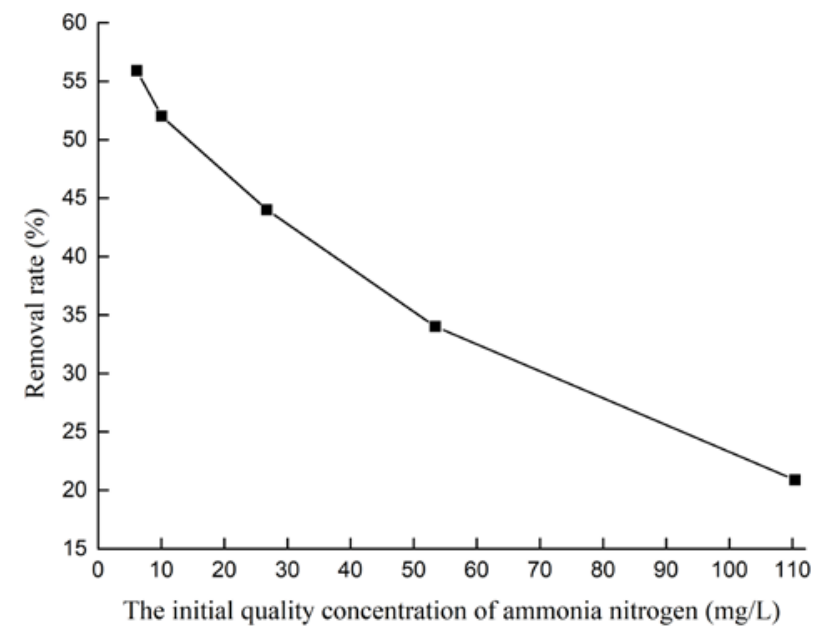

Fig.4. Effect of initial concentration on ammonia nitrogen removal.

\section{Conclusion}

According to the present research work, steel slag is a promising absorbent material for waste water treatment.
But there is still a problem of low adsorption capacity of steel slag. So it is necessary to broaden the modification methods of steel slag and seek to combine with other waste water treatment methods.

\section{Acknowledgment}

The research was financially supported by Central Public-interest Scientific Institution Basal Research Fund (No. CKSF2019407+SH).

\section{References}

1. H. Motz, J. Geiseler, Waste Manage, 21 (2001).

2. H. D. Meng, L. Liu, Steelmaking, 25 (2000).

3. C. H. Li, J. B. Yan,WISCO TECHNOLOGY, 47 (2009).

4. D. M. Proctor, K. A. Fehling, E. C. Shay, Environmental Science \& Technology, 8 (2000).

5. ĆurkovićL, ŠCerjan-Stefanović, Rastovèan-Mioè A., Water Research, 35 (2001).

6. Y. Y. Shen, Nanjing University of science \& technology, (2015).

7. Y. X. Xiao, Xihua University, (2017).

8. Y. Ma, Qingdao Technological University, (2010).

9. Y. H. Jiang, M. M. Liu, M. D. Qiu, Safety and Environmental Engineering, 19 (2012).

10. S. J. Ma, S. Y. Liu, Z. L. Hu, Non-Ferrous Mining and Metallurgy, 20 (2004).

11. N. N. Xia, Ocean University of China, (2013).

12. L. Y. Zhang, Z. R. Nan, Y. X. Zheng, 38 (2015).

13. X. H. Lai, C. Yan, X. L. Ren, Journal of North University of China, 39 (2018).

14. J. Duan, B. Su, Chemical Engineering Journal, 160 (2014).

15. H. L. Zheng, Y. L. Ge, Q. Y. Shou, Journal of Civil Architectural and Environmental Engineering, 38 (2016). 16. J. M. Duan, J. M. Lin, H. D. Fang, Chinese Journal of Environmental Engineering, 6 (2012).

17. J. B. Wang, X. Li, L.P. Qiu, China Water \& Wastewater, 35 (2019).

18. F. Q. Chen, R. Gao, H. P. Song, Chinese Journal of Environmental Engineering, 6 (2012). 